\title{
Factors Affecting Yi Ethnic Minority EFL Learners' English Pronunciation Learning in Leshan Normal University, Sichuan, China
}

\author{
$\mathrm{Gu}^{\mathrm{Min}}{ }^{1}$ \\ ${ }^{1}$ School of Foreign Language, Leshan Normal University, China \\ Correspondence: Gu Min, School of Foreign Language, Leshan Normal University, China.
}

Received: March 3, 2020

Accepted: May 19, 2020

Online Published: May 20, 2020

doi: 10.5539/elt.v13n6p104

URL: https://doi.org/10.5539/elt.v13n6p104

\begin{abstract}
In recent years, along with the development of Chinese economy, the Chinese government pays more attention to English education in ethnic minority areas. Chinese ethnic minority EFL learners' passion has reached an unprecedented level. Nevertheless, a series of complicated factors affect Chinese ethnic minority EFL learners' English pronunciation learning.

The paper adopts an in-depth interview method among Yi ethnic minority EFL learners in Leshan Normal University, and analyzes the main factors that affect learners' English pronunciation learning. Finally, the paper draws a conclusion to trigger the further study.
\end{abstract}

Keywords: Yi ethnic minority EFL learners, English pronunciation learning, local university

\section{Introduction}

China is one of the largest countries in the world, with nearly 1.4 billion population (World Statistics, 2019). It is consisted of 56 ethnic groups, including 55 ethnic minorities and the dominant Han. Among them, 93\% of the Chinese people are Han. Hence, $7 \%$ of the Chinese people are the non-Han Chinese, we call them ethnic minority (Ethnic Groups in China, 2019). Yi ethnic minority group is the largest ethnic minority groups in southwest of China. There are two Yi Autonomous Counties under the administration of Leshan city, Sichuan, China, including Mabian Yi Autonomous County and Ebian Yi Autonomous County. Therefore, Yi ethnic minority students make up a large proportion of ethnic minority students in Leshan Normal University. For Yi ethnic minority EFL learners, English pronunciation is with many difficulties compared to Han majority EFL learners'. Therefore, it is worthwhile to do an in-depth interview in order to analyze the main factors that affect Yi ethnic minority learners' English pronunciation learning. It will help teachers design and organize teaching in order to help students overcome these difficulties effectively.

\section{Previous Studies of English Pronunciation Instruction}

Hismanoglu (2006) declared that pronunciation instruction plays an important in English teaching, especially for oral communication. Because when learners begin to learn a new language and its pronunciation, they need to gradually develop new habits in order to overcome the difficulties resulting from their native language. That is to say, learners should be able to utter word combination in an general accepted way (Otlowski, 1998), making communication accessible.

James (2010) divides acceptable pronunciation into three levels. At the first level, what the speaker said was incomprehensible to the listener. The speaker's mispronounced English words or misused vocabulary /grammar lead to difficulties in oral communication. At the second level, the speaker's pronunciation can be understood by listeners, but the pronunciation is with strange accent, that is to say, the pronunciation is not authentic pronunciation. If a speaker's pronunciation is with heavy accent it will affect the listener's understanding (Morley, 1994); at the third level, people understand the speaker. This view is consistent with Scovell's (1988) opinion, the person who listens to you should be able to understand what you are saying with minimal obstacles, and it should be the purpose of English pronunciation instruction.

Actually, it is full of challenges to achieve the third level of teaching objectives,. There are many factors that affect the quality of pronunciation instruction. According to Harmer (2001), teacher is one of the most important factor influence student's pronunciation learning. However, a lot of teachers do not pay enough attention to English pronunciation on the ideological level, they think learning pronunciation is a waste of time; if the teacher 
himself has bad pronunciation, students will also have bad pronunciation. In the classroom with only teacher and students, Even if students are flexible enough to express themselves in English, therefore, Harmer (2001) stated the classroom is not a real language conversation situation because it just takes place at classroom. Because students do not the opportunity to talk with native speakers. There are some major factors that lead to this situation, the lack of professional quality, and appropriate teaching and learning materials, as well as the limited time to practice pronunciation that lead teachers not to pay enough attention to English pronunciation instruction.

Kenworthy's (1987) stated the factor from students' themselves, including learners' phonetic ability, integrative motivation and achievement motivation. Of course, on the other hand, teachers play an essential role to guide students to realize the importance of pronunciation at the beginning of learning English systematically. teachers should instill this idea in their students.

Butler-Pascoe and Wiburg (2003) stated that the aims of teaching pronunciation are to develop English that is easy to understand to the listener, develop English that meets persons' needs and produce communicative competence, help learners feel more comfortable in using English, cultivate a positive self-awareness just like non-native speakers in oral communication, develop personal speech monitoring skills and speech adjustment strategies that finally help learners develop in and out of the class.

\section{Research Design}

This study did in October 2019, which consisted of the following 3 stages: first, selecting research subjects and designing in-depth interview questions; secondly, conducting face-to face interview and collecting primary data; thirdly, analyzing the data; and finally, writing the paper.

\section{Research Subjects}

8 non-English majors Yi ethnic minority EFL learners were chosen randomly as the research subjects, including 4 female participants and 4 male participants, aged 18 to 20 enrolled in Leshan Normal University. They are with similar family and educational backgrounds. In addition, their level of English ranged from elementary to intermediate. They all started to study English as a foreign language from junior high school in Yi Autonomous Counties. Table 1 is the general background information of the participants with pseudonym used to protect their identities.

Table 1. Participants details

\begin{tabular}{ccccc}
\hline Name & Gender & Age & Major & $\begin{array}{c}\text { Language } \\
\text { proficiency }\end{array}$ \\
\hline Mashen & $\mathrm{M}$ & 18 & Special Education & Elementary \\
Zhangyu & $\mathrm{F}$ & 19 & Special Education & Low-intermediate \\
Aliushibu & $\mathrm{M}$ & 19 & Education & Elementary \\
Zhanling & $\mathrm{F}$ & 20 & Communication & Intermediate \\
Xiangyan & $\mathrm{F}$ & 18 & Chinese Literature & Intermediate \\
Lamu & $\mathrm{F}$ & 19 & Sport Science & Elementary \\
Dingle & $\mathrm{M}$ & 20 & Accounting & Intermediate \\
Wangze & $\mathrm{M}$ & 18 & Mathematics & Low-intermediate \\
\hline
\end{tabular}

\section{In-depth Interview Questions}

The interview questions about the English pronunciation learning are listed as follows:

1. What is your purpose of learning English?

2. What do you think is the biggest difficulty in learning English pronunciation?

3. How do you practice your English pronunciation on usual conditions?

Data collected from interview were coded using "open coding" (Strauss \& Corbin, 1998) firstly, the author attached the labels to the corresponding information. Then, data were sorted under core categories in order to identify related patterns and themes. Finally, the author would summarize the data in a way of "thick description" (Punch, 2003) expression.

\section{Procedures}

Before conducting the interview, 8 Yi ethnic minority EFL students are divided into two groups, each group 
contained 2 girls and 2 boys. Each group of $4 \mathrm{Yi}$ students is interviewed by one researcher. Interviewer introduced the goals and purposes of this interview to interviewees, including ensuring informed consent and confidentiality of the interviewee.

Researcher asked three open-ended questions. Then, the in-depth interviews were conducted in two different phases: at first phase, the informal conversational interview was used. The author did individual casual chats with Yi students. From the conversations with these Yi students, researchers had the impression that Yi students tried their best to cope with their English pronunciation when they first entered into university, and their ways of coping totally differed. At second phase, the interviews were with two purposes: first purpose was to explore topics for investigation, second purpose was to use them as pilot studies. Individual interviews with each student were carried out, using a mixed interview method. The results of this stage of interviewing focused on English pronunciation and English learning motivation, and with special attention being paid to Yi students' first language and their pronunciation difficulties. Researchers took notes and audiotape during the interview. Finally, the author summarized key data immediately following the interview and verified some key information given in interviews.

\section{Major Findings of the Research Results}

The interview found the main subjective and objective factors affecting the English pronunciation study of Yi ethnic minority EFL learners, which are listed as follows:

\subsection{Emotional Factors}

In the interview, the author found that the emotional factors affecting the English phonetic learning of minority students are the main influencing factors. These factors are various and have an indirect or direct effect on students' English pronunciation learning. 13 Yi students said, they never volunteer to answer when English teacher ask questions, even if they know the answers. They said that their pronunciation is not accurate, their spoken language is not as fluent as Han Chinese students, and they feel unconfident. This kind of psychology caused the decline of students' pronunciation learning motivation, and formed a vicious circle of learning. Two Yi ethnic minority students also have the subconscious of their own national characteristics, which has the rejection psychology to the whole foreign language learning, and prevents the foreign language input, which also directly affects the learning state of English pronunciation.

As Nourodin \& Zahra (2015) stated motivation is a fundamental factor in achieving pronunciation. Motivation is described as an intrinsic motivation or desire that promotes language learning (Qianmei, 2009). All Yi students in this study said that the main motivation of learning English is to pass final English exam of each semester and College English Test 4 (CET4) and finally to get a better job. But CET4 itself does not contain the oral assessment part. This is one of the reasons why Yi students don't pay attention to pronunciation. Just two Yi students said they plan to study abroad after finish their undergraduate study in China. Thus it an be seen Yi students' motivation to learn English is closely related to their personal development. Most of them are lack of urgency for English learning.

\subsection{Language Factors}

Yi ethnic minority EFL students have their own culture and native language, speaking Chinese as their second language and English as the third one. One aspect of Yi students' background became apparent during the interview: most of them speak native language with parents at home, but actually they do not know how to read and write in their native language any more. They are from Yi Autonomous County means that their English is less polished than that of some of their compatriots from big cities, though the fact that they had all gone through a rigorous selection process to enter into university. That is to say, when English teacher teach new vocabulary to them, they use Chinese to explain English meaning to students, and Chinese has naturally become a bridge for Yi ethnic minority students to learn English. Yi students can't understand English directly from their mother tongue. They have to change it through Chinese before they understand it. However, referring to pronunciation learning, Yi students have their own ideas and ways. One student, "Ma Shen" said:

"In my native language, there are some similar pronunciation to English. I feel I can use my mother tongue to help me learn pronunciation. My English teacher's first language is Chinese, not my native language. Sometimes I feel it is difficult to express my difficulties of pronunciation to her."

However, the Influence of Chinese on the Learning of English pronunciation also can not be neglected: Chinese is the second language that minority students come into contact with. Before entering the university to study English pronunciation, minority students have learned Chinese, they all know how to speak, listen, read and write in Chinese and they have formed the habit of Chinese pronunciation. They master Chinese better than their 
native language. Therefore, the knowledge of Chinese phonetics will inevitably affect the learning of English language. One student, "Zhangyu” said:

"I find my pronunciation is different from my Han Chinese friends. I know I speak English with heavy accent. Now I try to learn the English pronunciation through the Chinese pronunciation, but I feel much difficult."

Because of the influence of mother tongue and Chinese language on English pronunciation and the difference between the three languages, it is very difficult for Yi ethnic minority EFL students to distinguish between right and wrong and understand clearly, so that they feel the difficulty of learning English pronunciation.

\subsection{E-learning Factors}

Referring to the third interview question, participants' answers are similar. Yi students like to download some interesting apps on their mobile phone and practice pronunciation on usual conditions. The most popular apps which is used to practice pronunciation is "English Fun dubbing" app. One student, "Lamu" said,

“"repeat-after-me' voice-over app that allows you to mimic characters which I like from movies. Sometimes I upload my dubbing video to Wechat. I feel like I have become a professional dubbing specialist."

It can be seen that a variety of on-line video learning methods and apps is the way for students to practice oral pronunciation in their daily life. But because the teacher didn't arrange students' dubbing homework, students don't practice persistently. Students would like to be offered professional English phonetics class by university, even though they are non-English major students.

\section{Conclusion}

Just as analyzed above, the English pronunciation for Yi ethnic minority in university in western China is not as good as what is expected. There is a certain gap between the English proficiency of the minority students and the Han students before entering into university. However, after becoming undergraduate student, Yi and Han students accept the same English language courses, and some of them find it is difficult to catch up with English teaching progress. Thus I strongly called on the efforts from all sides to pay more attention to ethnic minority English pronunciation learning.

First, the schools and universities should add English oral assessment into each semester's final exam. Only in this way can the English pronunciation be paid more attention in a short time from teacher and students. Second, in university, non-English major minority students should be offered special English classes, rather than taking same English classes with Han students together. Ethnic minority students from different majors can be grouped together to take small size English classes. Use teaching materials suitable for their English proficiency, pay more attention to the cultivation of oral ability, and pay more attention to the study of practical English.

To sum up, the paper mainly discusses the main factors that affect learners' English pronunciation learning, with a purpose to recognize these factors objectively. In addition to the above factors, there are also the language ability, experience, knowledge and other factors of minority students themselves, as well as the relative lack of good English teachers, equipment and data sources in minority areas, which need to be further explored and studied.

\section{ReferenceS}

Butler-Pascoe, M. E. \& Wiburg, K. M. (2003). Technology and Teaching English Language Learners. MA: Pearson Education, Inc.

Ethnic Groups in China. (2019). 2020 China Discovery. https://www.chinadiscovery.com/ethnic-minority-culture-tour/ethnic-minorities-in-china.html

Harmer, J. (2001). The Practice of English Language Teaching. London: Longman. https://doi.org/10.1177/003368820103200109

Hismanoglu, M. (2006). Current Perspectives on Pronunciation Learning and Teaching. Journal of Language and Linguistic Studies, 2(1), 101-110.

James, R. B. (2010). Teaching Pronunciation Gets a Bad R.A.P: A Framework for Teaching Pronunciation. Hankuk: University of Foreign Studies.

Kenworthy, J. (1987). Teaching English Pronunciation. Longman, Harlow.

Morley, J. (1994). Pronunciation pedagogy and theory: New views, new directions. TESOL, 1600 Cameron Street, Suite 300, Alexandria, VA 22314.

Nourodin Yousofi \& Zahra Naderi farjad. (2015). The Relationship between Motivation and Pronunciation: A 
case of Iranian EFL learners. Journal of Applied Linguistics and Language Research.

Otlowski, M. (1998). Pronunciation: What Are the Expectations? The Internet TESL Journal, 5(1). Retrieved from June 26, 2016, from: http://www.iteslj.org./ Article / Otlowski poronunciation.html.

Punch, K. (2003). Introduction to Social Research Methods: Quantitative and Qualitative Approaches. Thousand Oaks, CA: Sage.

Qianmei, Zhang (2009). Affecting Factors of Native-Like Pronunciation: A Literature Review. 한국교육문제연구소 제27권 제2호, 33-52, 2009

Scovel, T. (1988). A time to speak: A psycholinguistic inquiry into the critical period for human speech. New York: Newbury House.

Strauss, A. \& Corbin, J. (1998). Basics of Qualitative Research (2nd ed.). Thousand Oaks, CA: Sage.

World Statistics. (2019). World's Most Populous Countries. https://www.infoplease.com/world/population-statistics/worlds-50-most-populous-countries

\section{Copyrights}

Copyright for this article is retained by the author(s), with first publication rights granted to the journal.

This is an open-access article distributed under the terms and conditions of the Creative Commons Attribution license (http://creativecommons.org/licenses/by/4.0/). 